\title{
Exploring salutogenesis as a concept of health and wellbeing in nurses who thrive professionally
}

\begin{abstract}
A Senior Honors Project Presented to the 1 Faculty of the Department of Nursing University of Hawaii at Manoa
\end{abstract}

In Partial Fulfillment of the Requirements for Bachelor of Science in Nursing with Honors

By Eleanor Stock April $12^{\text {th }} 2017$

Committee:

Dr. Estelle Codier, RN, MSN, PhD, Honors Mentor Janet Uyehara, RN, MS

Samantha Kaiser, Honors Committee Student Representative 


\section{Acknowledgements}

I am thankful for this opportunity provided by the University of Hawaii's School of Nursing and Dental Hygiene. This experience has provided me with the opportunity to learn, experience research, travel, and excel as a nursing student. Throughout this entire experience I have been supported and encouraged by many individuals, and I would like to express my gratitude to all those individuals involved.

I am thankful for my second semester instructor, Lori Hildebrandt, who encouraged me to become involved with the honors program, and provided me with the contact information for the nursing honors program.

My honors research advisor, and mentor, Dr. Estelle Codier, has been an inspirational guide throughout this process. On our initial meeting, I was blown away by Dr. Codier's passion for both nursing and research. It was her enthusiasm, which pushed me towards becoming involved in the honors program. Dr. Codier dedicated time to assist me in constructing and revising my PowerPoint, poster, and paper. Dr. Codier's commitment, and encouragement towards me and my work, were a catalyst in the success of my project.

I would like to thank my family for their encouragement to complete this project. Their words of wisdom and support helped me overcome any obstacles I faced.

I would like to thank the individuals who were on my honors committee board. I appreciate the time you all took to read and provide feedback on my work.

I would also like to thank the twelve nurses who volunteered their time to participate in my honors project. 


\begin{abstract}
Aim: To determine whether salutogenesis, a concept of health and wellbeing, can be identified in nurses who self-describe themselves as thriving professionally.

Background: Nurse burnout can potentially impact clinical performance, patient safety, and increase the turnover of nurses, which all contribute to additional health care costs (Rushton, Batcheller, Schroeder \& Donohue, 2015). The ability to not only avoid burnout, but to thrive in stressful environments is an important factor worth exploring. The salutogenic theory is related to this.
\end{abstract}

Methods: This was a mixed method, exploratory, descriptive study which was undertaken to describe elements of the salutogenic theory, in survey data, from twelve nurses who describe themselves as "thriving” professionally. Qualitative data was analyzed for themes. Quantitative data was compared to the salutogenic model.

Results: Qualitative data analysis revealed the importance of the following main themes: other people, passion, coping mechanisms, personal characteristics, and time. Quantitative data revealed the average Sense of Coherence (SOC) score, which measures a person's perceived health, was 73.58 out of a possible 91 points. Ranking of scores revealed the four highest scoring means all correlated to the meaningfulness category of the SOC questionnaire.

Keywords: Salutogenesis, Sense of Coherence (SOC), Generalized Resistance Resources (GRR), Nurses, Burnout, Thrive, Health, Wellbeing. 
Table of Contents

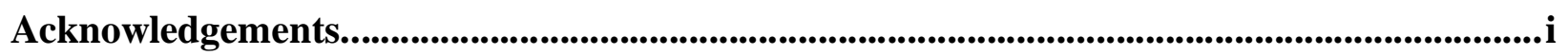

Abstract..........................................................................................................................................

List of Figures.............................................................................................................................................

Introduction........................................................................................................................................................1-2

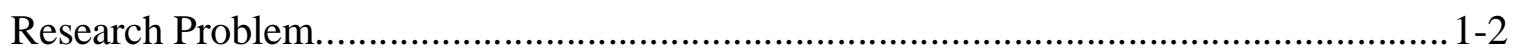

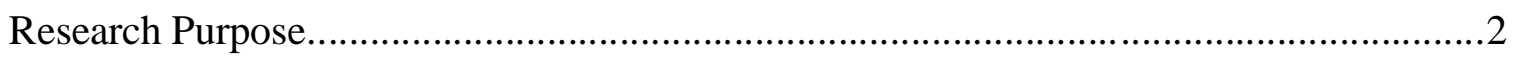

Theoretical Framework..............................................................................................................................2-4

Literature Review..................................................................................................................6

Objective...........................................................................................................................................................

Research Questions..........................................................................................................................7

Methodology.................................................................................................................................................7-12

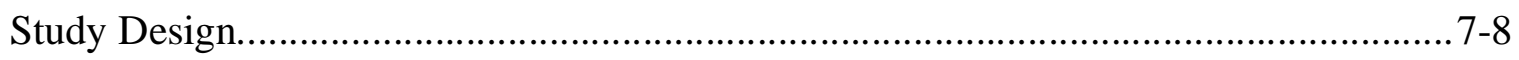

Ethical considerations........................................................................................... 8-9

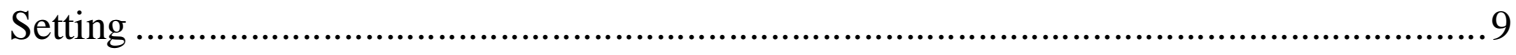

Sample

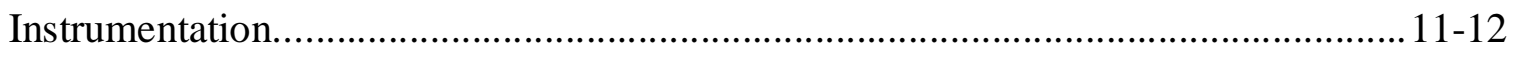

Data Collection and Analysis........................................................................................12

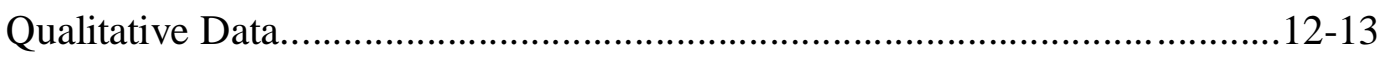

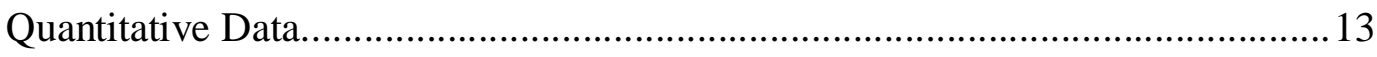

Analysis and Findings............................................................................................................................13-24

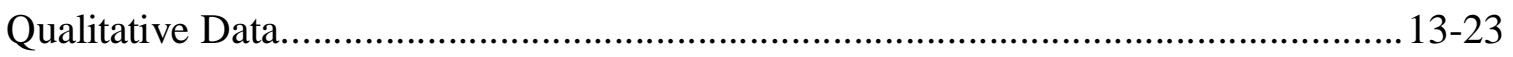

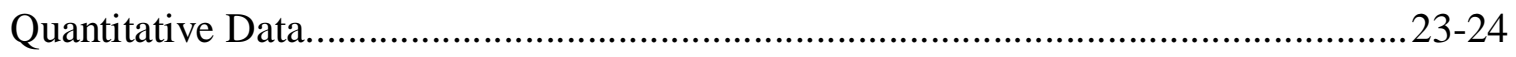

Discussion.......................................................................................................................................24-26

Recommendations....................................................................................................................26

Limitations...........................................................................................................................................26-27

Reflection..........................................................................................................................................27-28

Appendices........................................................................................................................................29-36 
Appendix A: Online Questionnaire via Survey Monkey........................................29-32

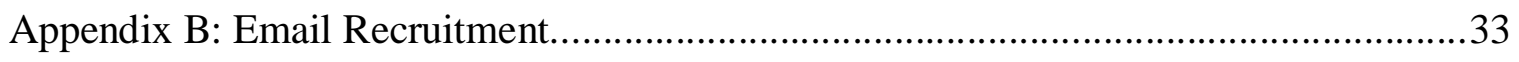

Appendix C: Sigma Theta Tau Newsletter Recruitment..............................................34

Appendix D: Email Response to Interest in participation..........................................35

Appendix E: University of Hawaii Consent to Participate in Research...........................36

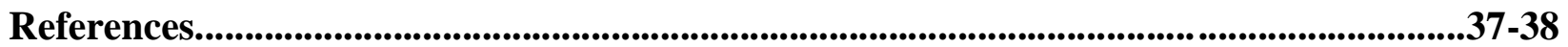




\section{List of Figures}

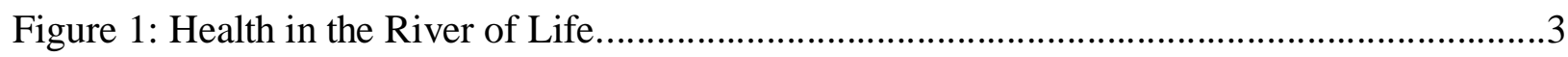

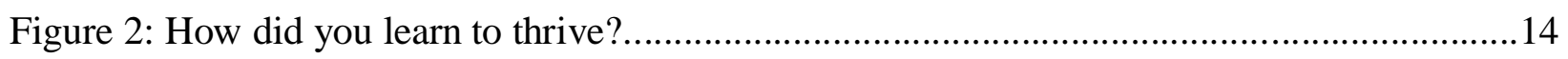

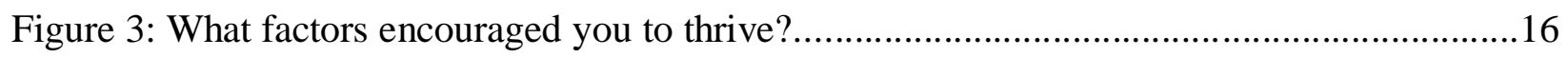

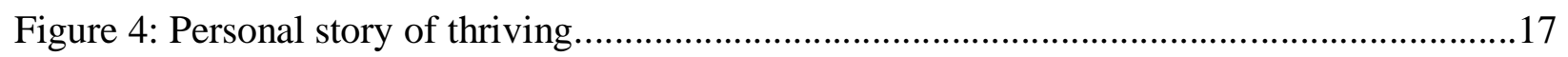

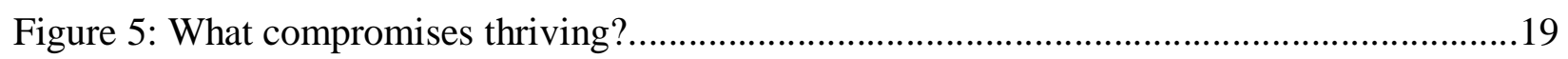

Figure 6: What strategies do you use when thriving is challenged?.....................................21

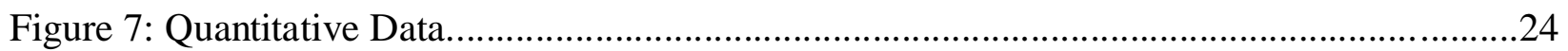




\section{Research Problem}

\section{Introduction}

Nurses face many potential factors every day which can challenge their sense of integrity and wellbeing. Nurses are integrated into a career in which they attempt to balance their personal and professional values. This can create high levels of stress, especially when nurses must act contrary to their personal values. Furthermore, nurses working in certain fields, such as criticalcare, oncology, and pediatrics, report high levels of stress and burnout (Rushton, Batcheller, Schroeder, \& Donohue, 2015). Burnout is defined as, "exhaustion of physical or emotional strength or motivation usually as a result of prolonged stress or frustration" (Merriam-Webster, 2016, p. 1).

Burnout is associated with poor health outcomes, increased turnover of nurses, and decreased patient satisfaction. In a study, one in five nurses voiced their intent to leave their position within one year (Rushton, Batcheller, Schroeder, \& Donohue, 2015). Additionally, "nurses with ten or more years of experience reported higher levels of moral distress than did nurses with fewer years of experience, suggestive of a cumulative impact" (Rushton et al., 2015, p.7). Nurse burnout is a serious issue as it can compromise the safety of both the patient and the nurse.

The ability of certain experienced nurses to not only avoid burnout, but to successfully thrive in a well-known stressful environment is a concept worth exploring. Salutogenesis is a concept created by the medical sociologist Aaron Antonovsky (1996). The term salutogenesis focuses on elements that support human health and wellbeing.

Early on in Antonovsky's career, research focused on finding causal relationships between certain risk factors and disease. Stress was noted as a negative event that would increase a person's susceptibility to disease (Lindström \& Eriksson, 2006). However, Antonovsky 
believed that stress and pandemonium was an inevitable part of life. Antonovsky became fascinated with how people manage to survive despite exposure to potential stressors and diseases.

Although Antonovsky's theory of salutogenesis is now being used as an umbrella term, it is still a relatively new concept and for some this may be a term they have not previously heard of. Salutogenesis has been explored in health domains such as nursing and midwifery, however this has been largely geared towards the patient rather than the practitioner's experience.

Currently there is a paucity of research available that links the concept of salutogenesis to nurses who have been able to successfully thrive in their profession. As there is more information available about the salutogenic theory, it is an opportune time to explore this gap in the knowledge.

\section{Research Purpose}

The purpose of this mixed method, exploratory, descriptive study, is to explore whether elements of salutogenesis are evident in nurses who self-describe themselves as thriving professionally.

\section{Theoretical Framework}

For this study, the salutogenic theory was utilized. This model focuses on identifying and attaining health. Antonovsky believed that often people become too fixated on disease and risks factors, which causes the disease to become the sole focus. This can prevent the delivery of holistic care. The salutogenic theory does not disregard a person's disease, or risk factors, but instead asks the question "How can this person be helped to move towards greater health?" (Antonovsky, 1996, p. 4). 
In this case a river is often used as a metaphor for health and is called, "Health in the river of life" (Lindström \& Eriksson, 2010). This metaphor illustrates the salutogenic theory. A person is always in danger in the river of life, for example from stress or disease, but the question is "How dangerous is our river? How well can we swim?" (Antonovsky, 1996, p. 4). In this illustration, curative medicine is devoted to "those who are drowning", and preventive medicine is to "those in danger of being pushed into the river upstream." Individuals need to shift their focus to actively pursue health promoting factors or salutary factors, as opposed to just being low in risk factors. The image below demonstrates the difference between care, protection, prevention, health education, and opportunities for health promotion (Lindström \& Eriksson, 2010).

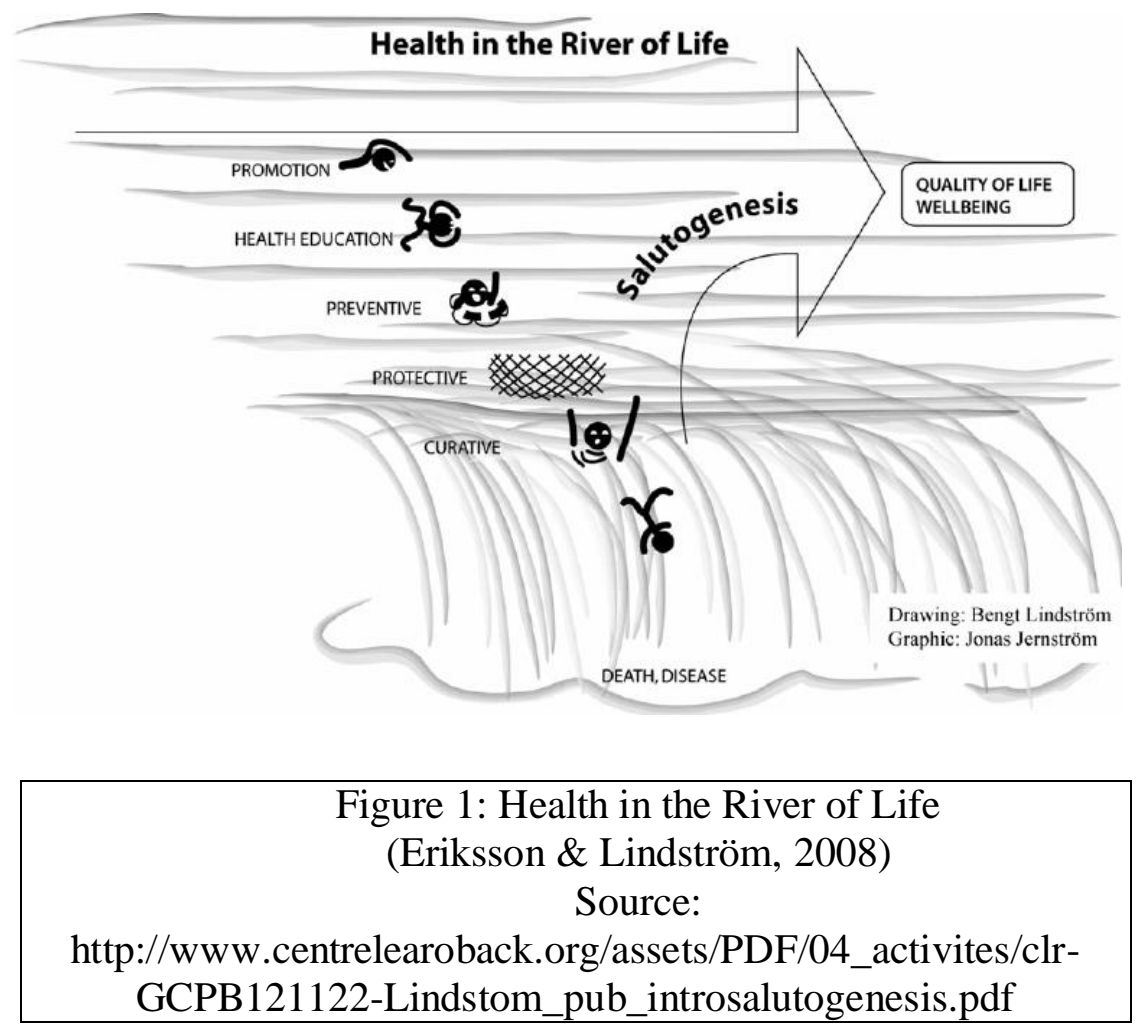

In Antonovsky's salutogenic theory he focuses on generalized resistance resources (GRR) and a person's SOC. GRR is a broad term used for resources that promote successful 
management of tension and stress. Antonovsky (1996) stated, "These refer to a property of a person, a collective or a situation which, as evidence or logic has indicated, facilitated successful coping with the inherent stressors of human existence.” Some examples of GRRs are: material resources, knowledge, coping strategies, social support, cultural stability, and a stable system of values and beliefs (Sullivan, 1989). Antonovsky was curious to discover what all these GRRs have in common and learned that, "they all fostered repeated life-experiences which, to put it at its simplest, helped one to see the world as making sense, cognitively, instrumentally and emotionally" (Antonovsky, 1996, p.5). This lead to the emergence of the sense of coherence (SOC) construct, "a generalized orientation toward the world which perceives it, on a continuum, as comprehensible, manageable, and meaningful" (Antonovsky, 1996, p.5).

Antonovsky suggested that the degree of a person's SOC in life influenced their position on the disease-wellness continuum. The three main components of SOC were the wish to be motivated and cope (meaningfulness), the belief that the challenge is understood (comprehensibility), and the belief that resources to cope are available (manageability). Antonovsky proposed the strength of a person's SOC is a significant factor facilitating the movement towards health. It is thought that the combination of GRR and a high SOC can facilitate health, and possibly thriving.

\section{Literature Review}

An extensive peer-reviewed literature search was completed using the University of Hawaii's online library database. The databases accessed were CINAHL, EBSCO Host, and Pubmed Medline. Websites of professional health organizations were also used. These sources were utilized to seek research on salutogenesis and thriving nurses. Key terms searched were: 
salutogenesis, sense of coherence, generalized resistance resources, burnout, thriving, nurses, health, and wellbeing.

A primary search of the term "salutogenesis" with a five-year limit yielded 19 results. However, the articles found did not link the concept salutogenesis with nurses, therefore, the search was broadened by removing the five-year limit. When the search was broadened 55 articles were found.

Most of articles found discussed salutogenesis and specific nursing or health issues. This category included 36 of the articles. Topics discussed in these articles included mental health, health promotion, rehabilitation, and public health. Some of these articles also identified certain populations such as adolescents, pregnant women, and those over 65. Additionally, certain articles mentioned a specific topic or diseases, such as nutrition, oral health, hypnosis, cystic fibrosis, and attention-deficit hyperactivity disorder. Even though these articles addressed nursing issues and patients, the articles did not investigate salutogenesis in nurses themselves.

Twelve of the articles found addressed the concept of salutogenesis. These articles provided good background information about salutogenesis. These articles explored the theory, scales, and meaning of salutogenesis, but did not mention applying this model to nurses.

During this search, it was interesting to find two articles which addressed salutogenesis and doctors. One of the articles was named, "Keeping Doctors Healthy: A Salutogenic Perspective" (Rabin, Matalon, Maoz, \& Shiber, 2005), and the other article investigated how the interaction between the ability of medical residents to cope with stress and their work might affect their level of job-related stress (Haoka, Sasahara, Tomotsune, Yoshino, Maeno, \& Matsuzaki, 2010). Both articles focused highly on sense of coherence, and the second article used Antonovsky's sense of coherence questionnaire in their study. 
Since the search of "salutogenesis" provided no articles that linked salutogenesis and nurses, a further search to include "salutogenesis" and "nurses" was completed. This yielded only 1 result. This article discussed the role of health assets, and how salutogenesis could impact it. However, again there was no literature linking the concept of salutogenesis and thriving nurses.

As the concept of this paper focuses on thriving, the concept of nurse burnout was explored to highlight the difficulty nurses face to not only cope, but thrive in a well-known demanding career. A literature search of "burnout," with a five-year limit resulted in 234 results. Many of these articles provided beneficial background data about the concept of burnout, and nurse fatigue. An article by Rushton, Batcher, Schroeder, and Donohue (2015) explored the concepts of burnout and resilience among nurses who work in high intensity settings, such as pediatrics, oncology, and critical care. Moral distress was found to be a significant preceptor of burnout, and in one study, "moral distress caused $25 \%$ of nurses in high-intensity work environments to leave their positions" (Rushton, Batcheller, Schroeder, \& Donohue, 2015, p.2). The primary investigator (PI) concluded that no published data exists that specifically explores the concept of salutogenesis in nurses who self-describe themselves as "thriving" professionally. In fact, the PI did not find any articles that linked salutogenesis and nurses. The literature search revealed salutogenesis is a term being explored, but has not been specifically addressed in nurses. It was also interesting how during the literature search, two articles explored the concept of salutogenesis and doctors.

It is evident that there is a gap in the knowledge concerning salutogenesis and nurses. This study aims to address the gap in the literature by exploring the concept of salutogenesis in self-described thriving nurses. 


\section{Objective}

The purpose of this study was to explore whether salutogenesis is a potential quality in nurses who self-describe themselves as "thriving" professionally. This connection has not been previously discussed.

\section{Research Questions}

Research questions of this study focused on exploring possible connections between the concept of salutogenesis and self-described thriving nurses. The questions aimed to be answered by this study are stated below:

1. Do nurses who describe themselves as "thriving" have salutogenic characteristics?

2. Do nurses who describe themselves as "thriving" have a high sense of coherence?

3. Do nurses who describe themselves as "thriving" use generalized resistance resources?

4. Are there common themes among the participant's responses?

\section{Methodology}

\section{Study Design}

This mixed method, exploratory-descriptive study, utilized a two-part survey questionnaire to collect quantitative and qualitative data from nurses who describe themselves as "thriving" professionally. Since there is no published data exploring the connection between thriving nurses and salutogenesis an exploratory-descriptive study was chosen.

This research was a convenience sample from nurses in Hawaii, who were recruited via email using snowball methodology (Appendix B), and through a nursing honors society. Snowball sampling is a non-probability (non-random) sampling method used when characteristics to be possessed by participants are specific and may be difficult to find. Snowball sampling method is based on referrals from initial subjects to generate additional subjects, and so 
acts to recruit others via chain referral (Dudovskiy, 2016). Additionally, an international nursing honors society, called Sigma Theta Tau (STT) was used to recruit participants (Appendix C). Sigma Theta Tau International (STTI) was founded in 1992, and now has over 135,000 active members that reside in more than 85 countries (Sigma Theta Tau International, 2016). The local chapter of the University of Hawaii, called Gama Psi Chapter, published a small recruitment paragraph in their newspaper, and allowed announcements about the research at their chapter meetings.

Once participants voiced their desire to be involved, a response email provided the questionnaire link, and a consent form (Appendix D and E). Qualitative data from the five open ended questions was collected and analyzed using thematic analysis. Quantitative data from Antonovsky's SOC-13 questionnaire was analyzed for SOC scores, patterns, and mean scores.

\section{Ethical Considerations}

As this study involved human participants, the approval of the study by the University of Hawaii’s Institutional Review Board (IRB) was required. The University of Hawaii's IRB is, "responsible for ensuring the protection in the rights, welfare, and safety of individuals who participate in research conducted by UH faculty, staff, and students" (University of Hawaii at Manoa, 2015, p.1). This study obtained the University of Hawaii's Institutional Review Board's approval prior to conducting the study.

This research was categorized as Federal Category 2 of the IRB Category of Exemption. As the research involved surveys of participants aged 18 years or older, that were not members of vulnerable populations, and all data was de-identified, this project was granted an exemption from the UH Manoa IRB. Subjects of this study were informed that participation was completely 
voluntary and participants could withdraw from the study at any time. Additionally, no data was reported in such a way that would identify any individual who participated in the study.

Certain other considerations were met to help ensure the research remained ethical. Once participants had voiced an interest to participate, they were provided with the survey link and a consent form. As this research involved a questionnaire which was considered relatively harmless, a signed consent form was not needed, but the participant's completion of the online questionnaire served as their consent (Grove, Gray, Burns, 2015). Additionally, to ensure the survey remained voluntary throughout, the survey was designed so participants did not need to answer one question before moving on to the next. This allowed the participants to leave the survey at any time.

Once participants had provided data for the research, the PI took steps to organize and secure the data. The information provided via Survey Monkey was anonymous, and the participants did not have to enter any personal information such as name, contact number, or email. The data was then moved to a word document and excel for organizational purposes. To ensure security and confidentiality of this data, the files were password protected, and the storage device was securely stored to prevent any chance of data being misused or interpreted without consent.

\section{Setting}

The study was conducted in a natural setting, which means the researcher did not manipulate or change the environment for the study (Grove, Gray, \& Burns, 2015). Once the participants vocalized their desire to participate in the study, the link for the online questionnaire was provided to the participants. The participants were then able to take the survey at any location or time. 


\section{Sample}

After the PI obtained an IRB exemption, participants were recruited. For this study, participants were required to fulfill certain criteria. The study had inclusion sampling criteria, which is defined as "the characteristics that the subject or element must possess to be part of the target population" (Grove, Gray, \& Burns, 2015, p. 251). The participants needed to meet the following criteria to participate in the study: 1) Self-described as thriving, 2) Experienced (10+ years working as a nurse), 3) Or recently retired nurse (within 1 year).

The sample for this study consisted of twelve $(n=12)$ nurses. Participants were asked five demographic data questions. Participants identified their gender as female (83.33\%), and male (16.67\%). Participants' age ranged from the category 35-44 to 75 and older. A further breakdown showed the participants identified themselves as between the ages 35-44 (16.67\%), 45-54 (16.67\%), 55-64 (33.33\%), 65-74 (25.00\%), and 75 and older (8.33\%). Participants identified themselves as white/Caucasian (50\%), Asian or Pacific Islander (33.33\%), Black or African American (8.33\%), and Other (8.33\%). The highest level of education obtained from the participants was stated as, Associate's Degree (0\%), Bachelor's degree (8.33\%), Master's degree (66.67\%), and $\mathrm{PhD}(25 \%)$. The higher education attainment level is perhaps reflective of nurses in the study needing at least ten years of registered nurse (RN) experience to participate. This also reflects the Institute of Medicine's (IOM) goal for nurses to participate in lifelong learning, and to double the number of nurses with a doctorate degree by 2020 (Institute of Medicine, 2010).

Participants were asked how many years of RN experience they had. Data revealed 33\% of participants had between 10 and 21 years of experience, and $67 \%$ of participants had 34 or more years of nursing experience. 


\section{Instrumentation}

The study involved a two-part questionnaire. The first survey questionnaire was developed specifically for this study. The second questionnaire was Antonovsky's SOC questionnaire. The online tool Survey Monkey was used to construct the questionnaire, and collect data from the participants. During the construction of the questionnaire several factors were taken into consideration. For example, the open-ended questions were structured so the PI could gain insight into the participant's life experiences, and gain information for the study. Five open ended questions were asked to participants (Appendix A).

The second part of the questionnaire involved using Antonovsky's SOC-13

questionnaire. A systematic review was done by Eriksson and Lindström (2005) to determine the validity of Antonovsky's SOC scale. They revealed that the SOC questionnaire has been used in at least 33 languages in 32 countries with at least 15 different versions of the questionnaire. The mean scores of the SOC-13 ranged from 35.39 (standard deviation [SD] 0.10) to 77.60 (SD 13.80) points across the studies reviewed. Eriksson and Lindström stated the, "SOC scale seems to be a reliable, valid, and cross culturally applicable instrument measuring how people manage stressful situations and stay well” (Eriksson \& Lindström, 2005, p.1).

For the purpose of this study, the SOC-13 (Antonovsky, 1987) was used to obtain quantitative data. The SOC 13-item scale is one of two original SOC scales. The SOC-13 item scale is rated on a seven point Likert scale. In addition to total SOC score, it yields three separate sub-scores corresponding to the components of the SOC concept: comprehensibility (questions: 2, 6, 8, 9, and 11), manageability (questions: 3, 5, 10, and 13), and meaningfulness (questions: 1, 4,7 , and 12). To score the SOC scale for a given participant, responses from items $1,2,3,7, \&$ 10 should be reversed (Mahammadzadeh, Poursharifi, \& Alipour, 2010). 
To test the functionality of the questionnaire a pilot was completed using five volunteers. The volunteers were asked to provide feedback about the questionnaire, and to state any suggestions they had. The volunteers believed the five open ended questions were appropriate at both making them reflect about their life experiences, and to provide information about the concept of thriving. Throughout this process three items were brought to the PI's attention. The three inquiries were 1) Does a retired nurse qualify to take the questionnaire? 2) A set definition of thriving may be helpful, and 3) Could the second part of the questionnaire about Antonovsky's SOC questionnaire be further explained?

After reviewing the feedback, each item was addressed. The PI decided that a nurse recently retired within one year would qualify to participate in the survey. The time limit of one year was chosen because this seemed like an appropriate time on which nurses would still be reflecting on their experiences as a nurse. After considering the feedback to add a definition of thriving, the PI decided against this. A key concept of this research was to explore and gain insight into what has made these individual nurses thrive. The PI felt that adding a set definition of thriving may persuade or change the participants own view of what it means to thrive. Lastly, to clarify the second part of the questionnaire a short paragraph was added above the questionnaire to explain the purpose of using Antonovsky's 13 question SOC questionnaire. The paragraph stated, "Below is a questionnaire that was developed by A. Antonovsky. It consists of thirteen questions. This questionnaire is used to measure a person's sense of coherence. It is thought that a person's sense of coherence could possibly be related to thriving."

\section{Data Collection and Analysis}

Qualitative Data. Qualitative data was analyzed using thematic analysis. Thematic analysis was used as it allowed the PI to move from a broad reading of data towards discovering, 
and identifying themes. Since this research focuses on exploring a new topic, thematic analysis was used to determine whether there were any similar themes between the respondents. First the PI became familiar with the data by re-reading the data many times. Codes were then developed, which identified important features of the data. The codes were then examined to identify broader patterns of meanings and potential themes.

Quantitative Data. Quantitative data was collected during Antonovsky’s SOC questionnaire. It was analyzed for statistical data such as mean, range, and patterns.

\section{Analysis and Findings}

\section{Qualitative Data}

Five open ended questions were asked to participants to gain insight into their view and experience of what it means to thrive.

The first question addressed asked participants "how did you learn to thrive?" This question aimed to gather introductory information about the participant's perspective on how they learned to thrive. The four major themes identified were: passion, other people/influences, education, and personal disposition.

The theme of passion was cited by $58 \%$ of participants as a key concept for learning how to thrive. One respondent described being "privileged to graduate" and "passionate to practice." This was also noted to be an expected part of the job role, with "people counting on my performance..." so there is "simply no room not to thrive!"

The positive influences of other people in learning to thrive was mentioned by $58 \%$ of participants. Family members, mentors, peers, and colleagues were seen as important influence.

Education was identified as an important feature of learning to thrive in $50 \%$ of participants. This included a broad range of formal and informal learning experiences: early 
education provided by family members in the home; learning accountability and responsibility from parents whilst growing up; the opportunity to ask questions; studying a broad range of traditional and contemporary subjects in school, and exploring new ways of thinking about self, mind and the world.

It was noted that innate personal characteristics assisted $33 \%$ of participants in learning to thrive. Participants noted having qualities such as a good sense of humor and a strong sense of survival. A strong sense of belief and confidence was also noted in participants. This is shown in the two responses, "I was born to do this", and "I have ALWAYS felt like I'm on the edge of something really fantastic..."

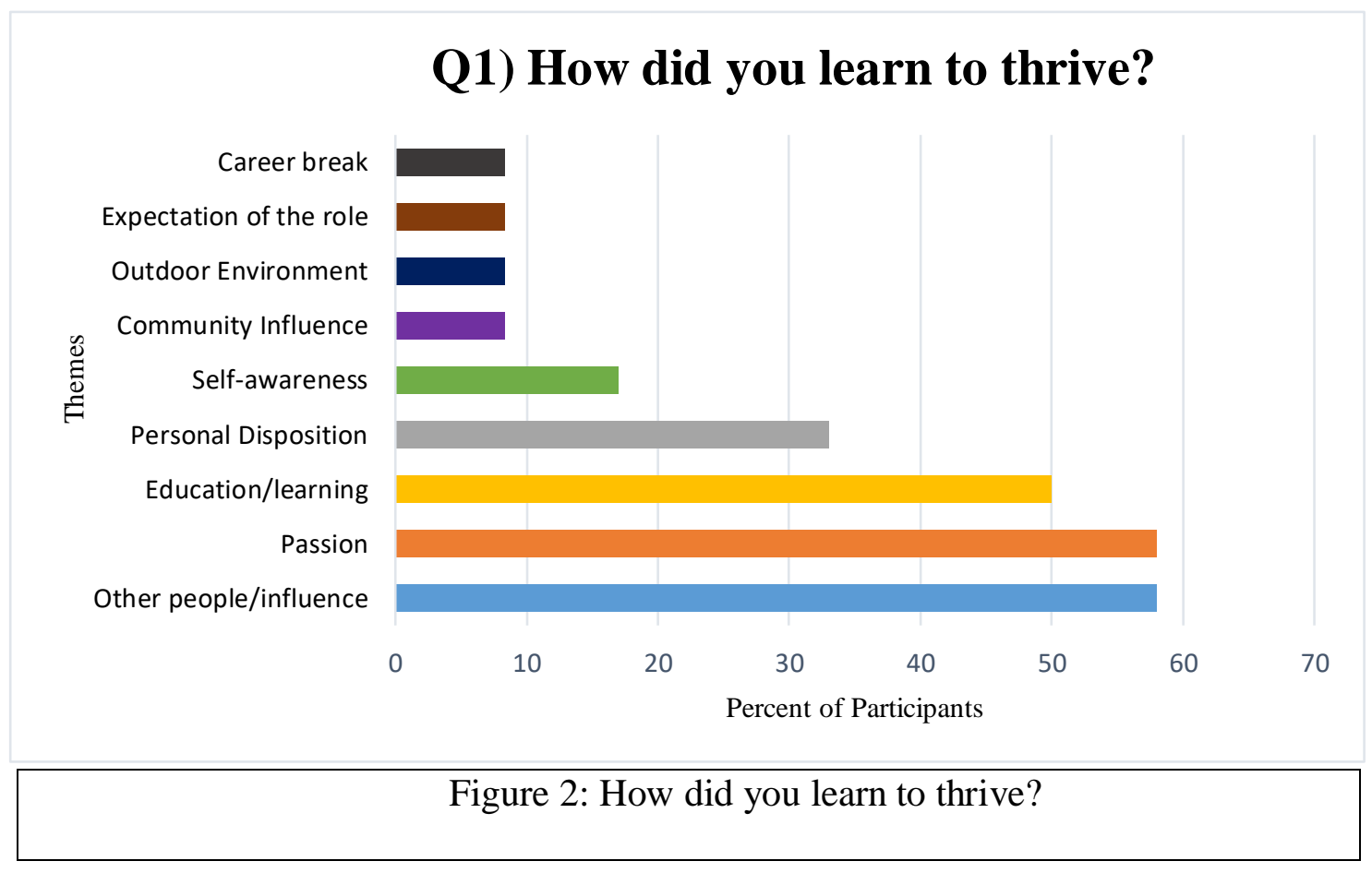

Question two addressed "what factors do you think have encouraged you to thrive?" The four chief themes identified were: passion, other people/influences, personal disposition, and self-awareness. 
Passion was noted as a concept that encouraged thriving in $50 \%$ of participants. This is illustrated by phrases such as: "I want to be the best I can be", "I love being a nurse", and “determined to be successful." One participant was also open about being "candid" with nurses who did not have passion for their work.

The influence of other people, both positive and negative, was vocalized by $50 \%$ of participants in their success to thriving. Mentors and guides, current nurse educators, and childhood/life experiences were seen as positive stepping stones towards thriving. Personal negative experiences such as "inadequate parenting", “divorce", and "sexual abuse", were all noted as events that provided clarity and drive to thrive.

Innate personal characteristics were reported by $42 \%$ of participants as a key aspect which encouraged thriving. Participants vocalized their own personal dispositions such as being confident, persevering, and having a positive outlook on life. One participant noted that both their ethnic background, and their own personal drive helped them thrive. For one respondent, their innate personal characteristics highlighted the importance to embrace reality, be adaptable, to enjoy life, help others, and be humble. They stated, "there is always a solution", "I "advocate for others", and "do not crave or seek accolades, applause...or honors."

Self-awareness was identified as a concept that encouraged thriving in $42 \%$ of the participants. Self-awareness was conveyed by statements showing clear perception of individual personality, strengths, weaknesses, thoughts, beliefs, motivation, and emotions. Statements such as, "I was in the driver's seat of success", "I could not rely on others for my happiness" and "I have the ability to choose my thoughts, words, \& actions", expresses the notion of knowing the importance of relying on one's own strengths. 


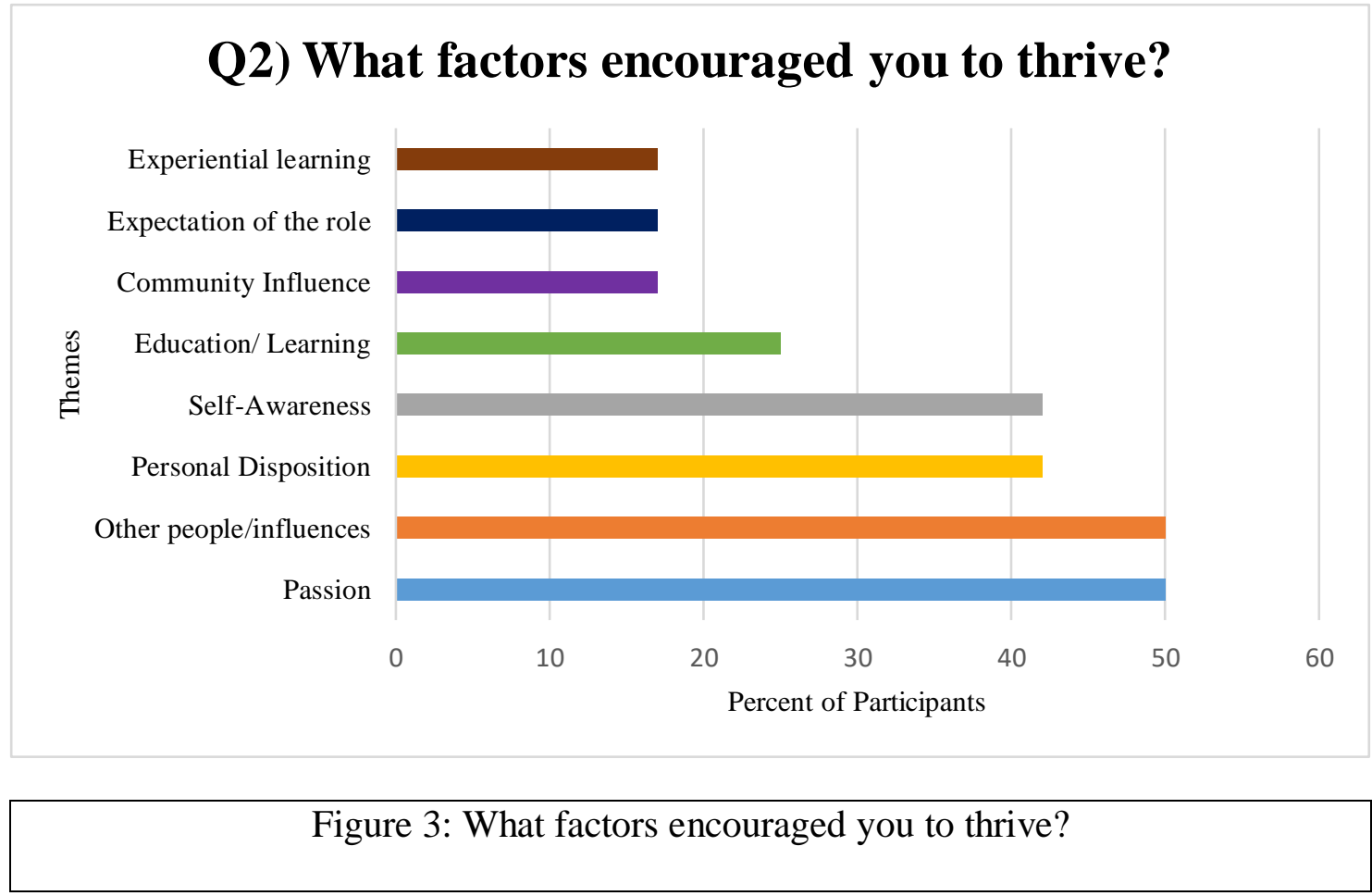

Question three aimed to discover whether there were any common themes of thriving in personal stories of thriving. The question asked, "can you provide a story that illustrates in some way how you learned to thrive?" Although each participant had a unique story to tell, there were prominent themes among the stories. The five principal themes noted were: challenges, education, other people/influences, experiences, and coping mechanisms.

A challenge was noted as a theme in $67 \%$ of participants' stories. Certain participants faced personal challenges such as a loss of a loved family member. Another participant noted how it was challenging dealing with "many patient deaths." Challenges were both seen as positive and negative events that helped thriving. One participant noted a connection between a challenge and thriving, "my personality thrives on a challenge." A further participant stated how fortunate they were to be in a learning environment that promoted "challenging growth."

Education was noted by $67 \%$ of participants in their personal stories. The participants noted their own desire to learn, be taught and, teach others. 
Other people being influential was noted in personal stories in $42 \%$ of participants.

Support from role models, educators, and mentors were mentioned.

Life experiences were voiced as a common theme in $33 \%$ of participants's stories. One participant's experience as a "foreign exchange student" led to additional experiences. Another participant noted nursing as being an "infinite platform" for experiences. It was also mentioned how experiences foster the "can do outlook."

In the personal accounts, $33 \%$ of participants noted the use of coping mechanisms.

Coping mechanisms such as music, journaling, time off, determination, and using talents were stated.

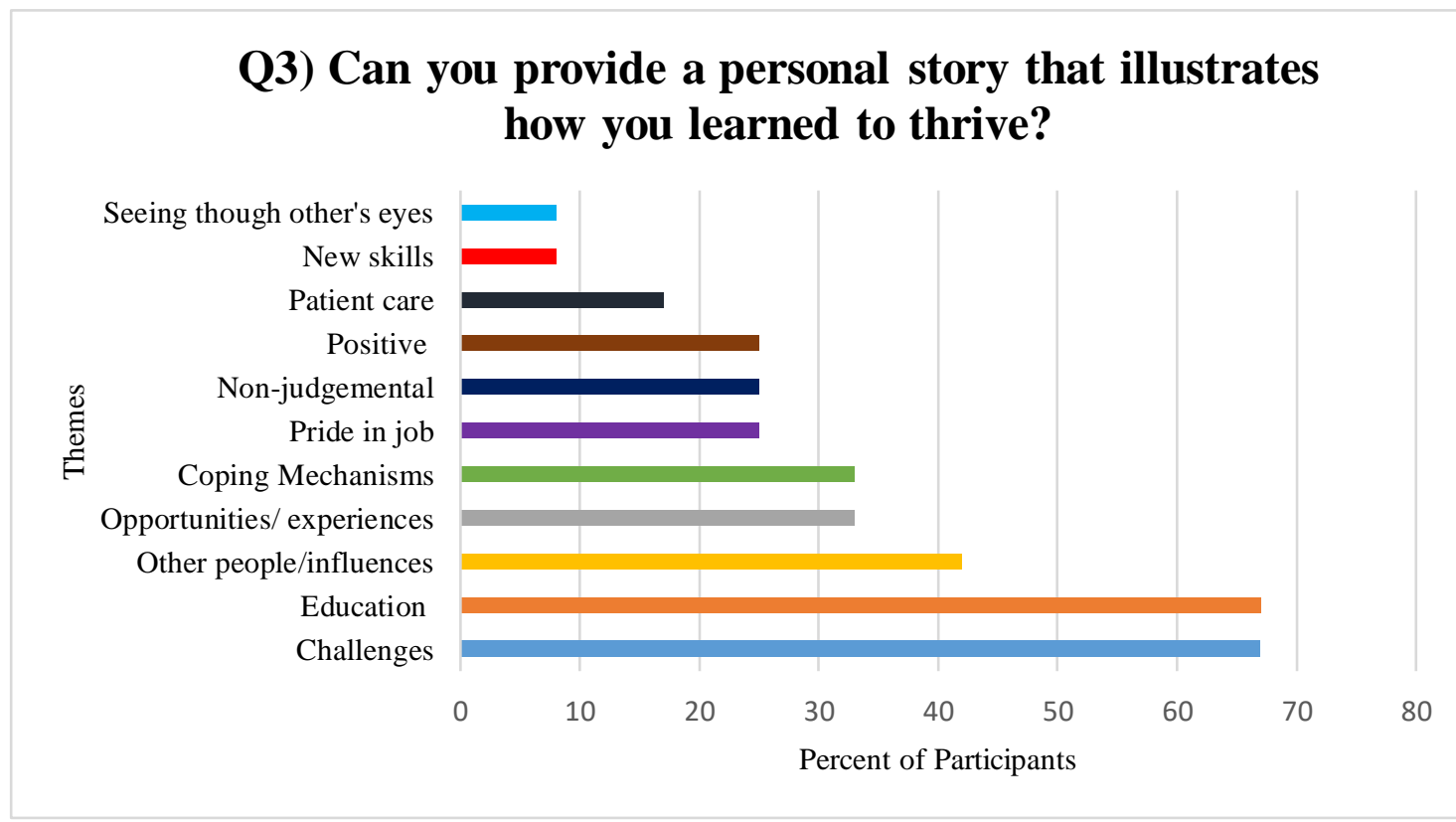

Figure 4: Personal story of thriving

Question four asked the question "what factors compromise you from thriving?" This question attempted to address what obstacles may interfere with thriving. Two chief themes were expressed which were being overworked, and time. Three smaller themes were also identified in 
$25 \%$ of participants. These themes were: feeling undervalued, over commitment, and losing focus on the patient.

Time was noted as a factor that compromised thriving in $42 \%$ of participants. Participants voiced their feelings of having too little time, feeling rushed, and the difficulty of striking a balance between work and personal time. One participant stated they had limited time to, "complete basic nursing care", and they always felt, "hurried and rushed." Another participant also stated the feeling of having to, "rush to a decision."

Being overworked was also noted as a compromising factor in $33 \%$ of participants. Terms such as, "working short," "overworked", and "energy and fatigue" were stated.

Feeling undervalued was a concept that compromised thriving in $25 \%$ of participants. One participant felt "a sense of injustice" when their own work was claimed by others. The second participant stated that "negative forces," and "politics" in the workplace can interfere with thriving.

Over-commitment was verbalized by $25 \%$ of participants as a factor that could compromise thriving. These participants stated, "over-commitment to professional activities", "overachievement", and "getting in a work situation that is hard to leave", which appears to reflect the dilemma between professional dedication to their work and their own sense of wellbeing.

The theme of losing focus on the patient was noted in $25 \%$ of participants. One participant stated that "over-helping" can be an issue, and they noticed that they "began to do for others what she/he is clearly capable of doing." Another participant believed that "because we've always done it that way" is not an acceptable way to provide patient care when there are 
better alternatives. The participant continued to state that some people "don't understand how seriously they impact patients."

Smaller themes were stated by one or two participants. These include boredom with routine, not seeking support, not taking responsibility, emotionally over involved, and making assumptions.

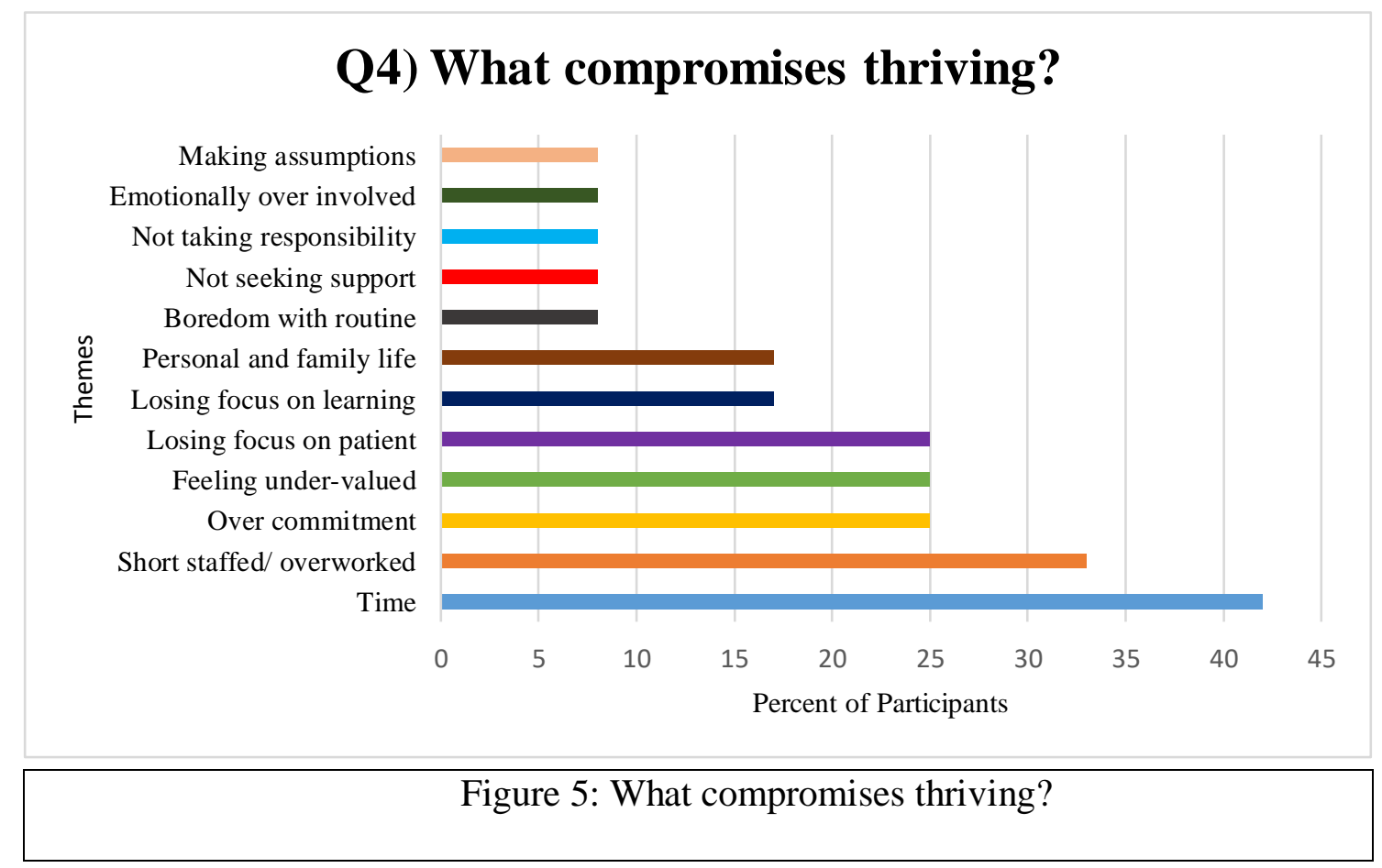

Question five asked participants "what strategies do you use when thriving is challenged?" This question aimed to discover what participants do when they are faced with an obstacle. It also aimed to explore the salutogenic concept of GRR. Four main themes were identified, and these were to focus on goals, use coping mechanisms, time, and other people/influences.

It is noted that $58 \%$ of participants said that when thriving is challenged it is important to stay focused on goals. One participant identified the importance of continual movement towards 
one's goals. A second participant simply stated "focus on goals." An additional participant noted the importance of "letting go of what's not mine, holding to purposeful boundaries between me, the students, \& the patients." Goals, both personal and work related seem to be an important factor to help redirect the participant to thriving.

When thriving is challenged, $50 \%$ of participants relied on coping mechanisms. These included swimming, meditation, praying, reading, and writing.

Also, when thriving is challenged, $50 \%$ of participants noted the importance of taking time to think and re-organize thoughts. This is portrayed in the comments, "take a break from it", "Stop...reorganize", and have "alone time." One participant also noted that it's important to not dwell on the things a person "didn't have time to do." Another participant noted the importance of "taking time away from relentless decision making, problem solving, and thinking..."

The support of other people was noted in $42 \%$ of participants' answers as strategies for when thriving is challenged. Participants reached out for fellow family members and friends, "I call my sister", "go out with friends", and "visit parents." One participant noted the importance of having a "cadre of friends" that support each other. Another participant noted the importance of stepping aside to let someone else "take the lead, and then support that person."

Two other smaller themes were identified as strategies used when thriving is challenged. These were having a positive attitude and using resources.

A positive attitude was noted as important by $33 \%$ of participants. This is displayed by the following statements: "look at the big picture", "I can do anything I so desire", and "wonderful career." 
The importance of utilizing resources was noted by $25 \%$ of the participants. This included the use of "material and human resources", and networking at conferences and committees.

Smaller themes noted by one or two participants were reflection, be clear, and learn new skills.

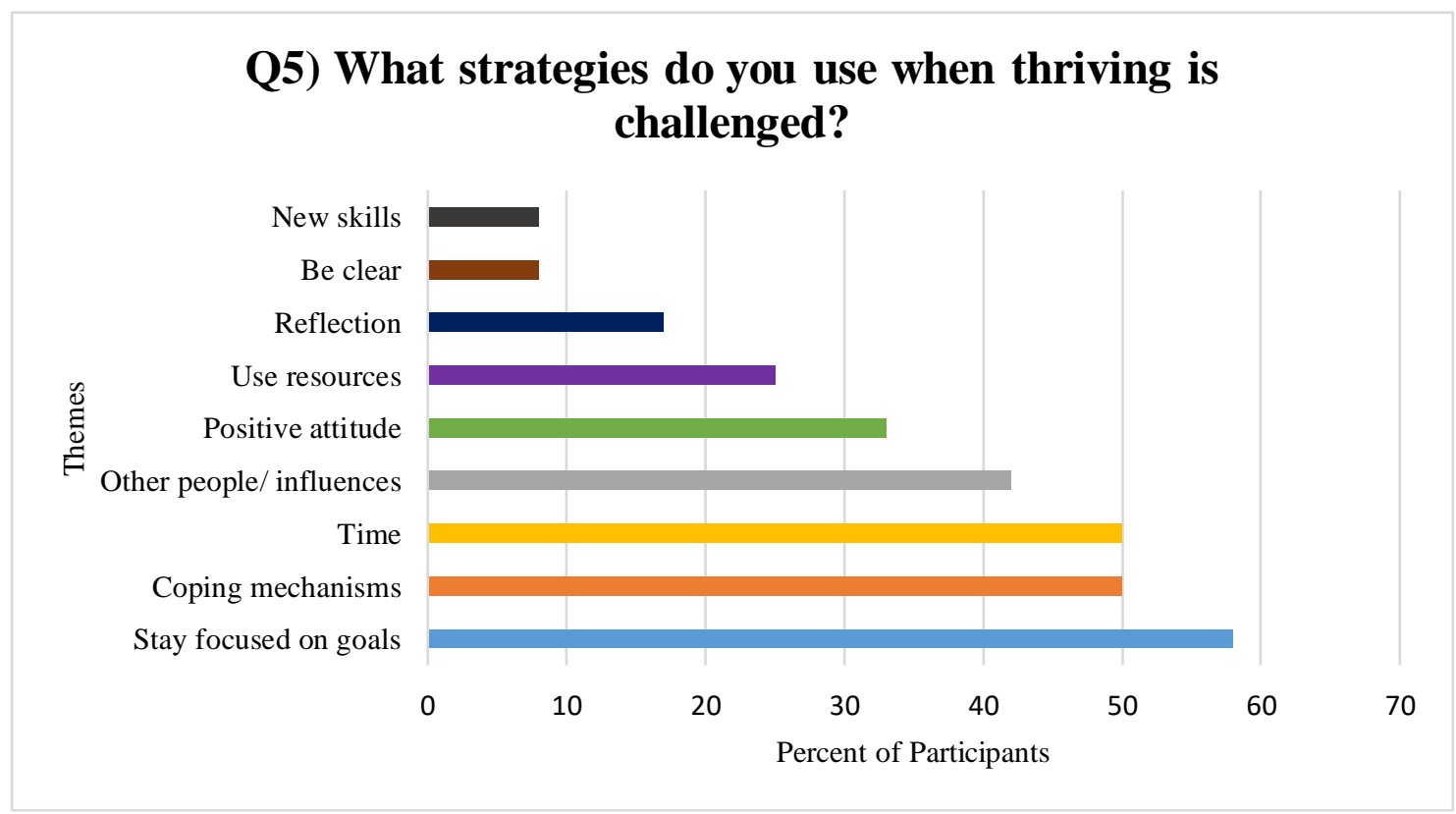

Figure 6: What strategies do you use when thriving is challenged?

These five open ended questions aimed to collect insight into the way in which these selfdescribed "thriving nurses" learned to thrive, sustain thriving, and what they do when thriving is challenged. Common themes were identified in each of the questions asked, and additionally similar themes appeared throughout all the questions. The theme "other people/influences" was mentioned in four out of five questions or $80 \%$. The only time other people was not mentioned was in question four, "what factors compromise you from thriving." The support and availability of other people, such as friends and family seems to be a key aspect in attaining and maintaining 
thriving. Passion, education, personal disposition, time, and coping mechanism were also mentioned in two out of five questions or $40 \%$.

Passion was the highest theme noted in both question one (how did you learn to thrive?), and question two (what factors do you think have encouraged you to thrive?). Passion towards nursing seems to be a critical characteristic that not only helped participants learn to thrive, but also encouraged thriving. Additionally, personal disposition was also noted as a theme in question one and two. These personal innate characteristics such as humor, strong sense of survival, ethnic background, and confidence, helped these nurses thrive.

The theme of education was a chief theme in question one (how did you learn to thrive?) and question three (can you provide a story that illustrates in some way how you learned to thrive?). In fact, education was the highest mentioned theme in question three. It seems that these thriving nurses believe in the concept of lifelong learning, and that education does not end after graduation. These thriving nurses have the desire to learn, be taught, and teach others. As one participant said, "if I don't have a skill, I seek to learn it."

The use of coping mechanism was apparent in the personal stories of thriving (question three), and question five (what strategies do you use when thriving is challenged). Coping mechanisms was the second highest theme in question five. The participants seem to have learned to use coping mechanism when faced with a challenge. These coping mechanisms included exercise, music, reading, knowledge, meditation, and praying. This concept also fits with Antonovsky's concept of GRR. Antonovsky states GRR promote successful management of tension and stress. From the answers provided to question five, these self-described thriving nurses have learned from life experiences ways to cope and deal with obstacles. 
It was interesting to discover how time was both an obstacle to thriving, and a solution when thriving is challenged. Time was a principal theme in both question four (what factors compromise you from thriving?), and question five (what strategies do you use when thriving is challenged?). Time, specifically the lack of time was mentioned as the highest theme in question four. These nurses felt that the lack of time compromised both their decision making, and nursing care. Feeling rushed was noted as a common obstacle to thriving as a nurse. On the other hand, time was also noted as a strategy used when thriving was challenged. During question five the focus was on slowing down, taking a break, and having alone time.

\section{Quantitative Data}

Quantitative data from Antonovsky's SOC-13 questionnaire revealed that the average SOC score was 73.58 out of a possible 91 points. The data range was 41-86 points. There was one participant who scored significantly lower than the other participants. If this score was omitted, the data range would have been 68-86 points. For each of the thirteen questions the mean was calculated from the participants' responses. These means were then ranked in order from highest mean to lowest mean to determine if there was any category that stood out. The SOC-13 questionnaire measures three main categories, which are meaningfulness (Q1, Q4, Q7, and Q12), comprehensibility (Q2, Q6, Q8, Q9, and Q11) and manageability (Q3, Q5, Q10, and Q13). The rankings revealed the four highest scoring means all correlated to the meaningfulness category. The meaningfulness category identifies the person's idea that their life demands are challenges worthy of engagement. It also signifies their wish to be motivated and succeed. Between the two other categories, the manageability questions produced the next highest mean. 
Manageability is the person's idea that they have the resources to cope. Lastly, the comprehensibility section produced the lowest overall mean. Comprehensibility refers to the person's internal and external stimuli, and if they are structured, predictable, and understandable. The data showed these thriving nurses feel like what they do is meaningful, enjoyable and has an important purpose.

\section{PARTICIPANTS}

\begin{tabular}{|l|c|c|c|c|c|c|c|c|c|c|c|c|c|c|}
\hline & $\mathbf{1}$ & $\mathbf{2}$ & $\mathbf{3}$ & $\mathbf{4}$ & $\mathbf{5}$ & $\mathbf{6}$ & $\mathbf{7}$ & $\mathbf{8}$ & $\mathbf{9}$ & $\mathbf{1 0}$ & $\mathbf{1 1}$ & $\mathbf{1 2}$ & Mean & Rankings \\
\hline Q1 & 7 & 7 & 5 & 6 & 7 & 2 & 7 & 6 & 5 & 4 & 7 & 6 & 5.75 & 4 \\
\hline Q2 & 3 & 5 & 6 & 6 & 3 & 3 & 4 & 6 & 5 & 6 & 6 & 6 & 4.92 & 10 \\
\hline Q3 & 4 & 6 & 4 & 6 & 3 & 2 & 5 & 6 & 5 & 6 & 6 & 6 & 4.92 & 9 \\
\hline Q4 & 7 & 7 & 7 & 6 & 7 & 6 & 7 & 6 & 6 & 6 & 7 & 7 & 6.58 & 1 \\
\hline Q5 & 7 & 6 & 6 & 6 & 2 & 3 & 6 & 6 & 5 & 7 & 6 & 7 & 5.58 & 6 \\
\hline Q6 & 6 & 6 & 6 & 6 & 7 & 6 & 7 & 6 & 5 & 2 & 6 & 7 & 5.83 & 5 \\
\hline Q7 & 7 & 7 & 6 & 6 & 6 & 6 & 7 & 6 & 5 & 4 & 7 & 7 & 6.17 & 3 \\
\hline Q8 & 5 & 7 & 6 & 4 & 7 & 1 & 6 & 6 & 5 & 7 & 6 & 7 & 5.58 & 6 \\
\hline Q9 & 6 & 7 & 6 & 3 & 7 & 1 & 6 & 5 & 5 & 7 & 7 & 7 & 5.58 & 6 \\
\hline Q10 & 4 & 7 & 6 & 5 & 5 & 3 & 6 & 5 & 5 & 7 & 6 & 6 & 5.42 & 7 \\
\hline Q11 & 3 & 7 & 5 & 5 & 4 & 2 & 5 & 5 & 5 & 7 & 6 & 6 & 5.00 & 8 \\
\hline Q12 & 7 & 7 & 7 & 5 & 7 & 5 & 7 & 7 & 6 & 6 & 7 & 7 & 6.50 & 2 \\
\hline Q13 & 5 & 7 & 6 & 6 & 3 & 1 & 7 & 7 & 6 & 7 & 7 & 7 & 5.75 & 4 \\
\hline T0TAL & 71 & 86 & 76 & 70 & 68 & 41 & 80 & 77 & 68 & 76 & 84 & 86 & 73.58 & \\
\hline
\end{tabular}

$\begin{array}{lll}\text { Meaningfulness } & \text { Q1, 4,7, 12 } & \text { total average }=6.25 \\ \text { Comprehensibility } & \text { Q2, 6, 8, 9, 11 } & \text { total average }=5.38 \\ \text { Manageability } & \text { Q3, 5, 10,13 } & \text { total average }=5.41\end{array}$

Figure 7: Quantitative Data

\section{Discussion}

The focus of this study was to determine whether nurses who describe themselves as thriving demonstrate salutogenic characteristics. There is a need to apply the salutogenic theory 
to nurses, therefore this attempt could act as grounds for further research. This research aimed to answer four questions.

Research Question 1: Do nurses who describe themselves as "thriving” have salutogenic characteristics?

- These self-describing nurses did demonstrate characteristics of salutogenesis by demonstrating their possession of both a high SOC, and the use of GRR.

- The commonly identified GRR were knowledge, coping mechanisms, social support and resources.

Research Question 2: Do nurses who describe themselves as "thriving" have a high sense of coherence?

- The thriving nurses have a higher mean SOC when compared to the systemic review done by Eriksson and Lindström (2005).

Research Question 3: Do nurses who describe themselves as "thriving” use generalized resistance resources?

- In the open-ended questions, the nurses voiced their use of GRRs.

The GRRs used were coping mechanism such as swimming, meditation, praying, reading, and writing. The participants also relied on support from others, having a positive attitude, and staying focused on goals.

Research Question 4: Are there common themes among the participants' responses?

- Common themes for each open-ended question was apparent. The support and influence of other people, such as friends, mentors, and family seems to be a key aspect in thriving.

- A passion towards a person's profession seems to influence thriving.

- Thriving is supported by learned experience such as education, and coping mechanisms. 
- Innate personal characteristics was noted as stepping stones to successfully thriving.

- Time was both an obstacle to thriving, and a solution when thriving is challenged.

\section{Recommendations}

In light of this project, further research should be done to explore the concept between salutogenesis and nurses. Future research should explore the high SOC scores in thriving nurses, and the use of GRRs.

Further investigation of which factors influence thriving and salutogenesis is warranted. Other concepts such as the age of the participant should be explored, because certain research states a person's SOC increases with age. The influence of professional nurse experience and salutogenesis needs to be explored, for example the concept of thriving and salutogenesis should be explored on nurses with no minimum years of experience.

\section{Limitations}

Due to limited time and resources, only 12 participants were included in this research study. However, most this study was qualitative data so there is less of an issue with limited data hindering statistical tests, as it would if the data was solely quantitative. Qualitative data can provide rich information from small number of participants, however, a larger number of participants may have strengthened any relationships identified.

All participants were nurses working in Hawaii and so the results of this study may not be generalized to nurses in other locations and populations without further studies.

There may be limitations in the exploration of common themes chosen based on the open-ended questions. The findings concluded from the open-ended question were determined based on an individual's observations of the data collected. There may have been biased opinion when grouping similar terms into categories. 
Furthermore, the population of participants were self-selected or referred to the study by another person, and may not be representative of all self-described thriving nurses. Additionally, no formal definition of thriving was provided. This was considered but was decided against because a key concept of this research was to explore and gain insight into what has made these individual nurses thrive. If a set definition of thriving had been provided, it may have persuaded or changed the participant's own view of what it means to thrive.

\section{Reflection}

As the PI of this project, I am very proud to have completed this project. I was raised and attended school in the United Kingdom. The education system is very different compared to the United States, and universities do not offer honor programs in the same way. Therefore, without the encouragement from my second semester clinical instructor, I would not have experienced this great opportunity. This process has allowed me to delve further both into nursing and research. I have learned valuable skills in organization, presenting, and writing.

I was fortunate enough to present my research poster at the Sigma Theta Tau European regional conference in Utrecht, Netherlands. I was able to attend my first nursing conference, talk about my research, network, and learn so much from other nurses and guest speakers. I was also invited by a nursing instructor at the University of Utrecht to have a skype conference with his nursing students to introduce them to the term salutogenesis, and research.

I am proud to say that my work was accepted and published by the British Journal of Nursing. I would like to thank the participants of the study, my honors advisor Dr. Estelle Codier, the honor committee members, and my family. This experience has made a lasting impact on my undergraduate nursing degree, and sparked a passion for future research. 


\title{
Appendix A
}

\section{Online Questionnaire via Survey Monkey}

\author{
What makes you thrive?
}

$\underline{\text { Part } 1}$

1. What is your gender?
○ Female
○ Male

2. What is your age?
○ 25-34
○ $35-44$
○ 45-54
○ $55-64$
○ $65-74$
○ 75 or older

3. What is your ethnicity?

- American Indian or Alaskan native

- Asian or Pacific Islander

- Black or African American

- Hispanic or Latino

- White/ Caucasian

- Prefer not to answer

O Other (please specify)

4. What is the highest level of school you have completed or the highest degree you have received?

- Associate degree

- Bachelor degree

- Master degree

○ Doctorate Degree

○ $\mathrm{PhD}$

5. How many years of nursing experience do you have?

6. How did you learn to thrive?

7. What factors do you think have encouraged you to thrive?

8. Can you provide a story that illustrates in some way how you learned to thrive? 
9. What factors compromise you from thriving?

10. What strategies do you use when thriving is challenged?

$\underline{\text { Part } 2}$

Below is a questionnaire, that was developed by A. Antonovsky. It consists of thirteen questions. This questionnaire is used to measure a person's sense of coherence. It is thought that a person's sense of coherence could possibly be related to thriving.

1. Do you have feeling that you don't really care about what goes on around you?
1
2
3
4
5
6
7

very seldom

very often

or never

2. Has it happened in the past that you were surprised by the behavior of people whom you thought you knew well?
1
2
3
4
5
6 7

never happened always happened

3. Has it happened that people whom you counted on disappointed you?
1
2

3

4

5

6

7

never happened

4. Until now your life has had:
1
2

3

4

5

6

7

no clear goals

or purpose at all

always very clear goals and purpose

5. Do you have the feeling that you're being treated unfairly?

1

2

3

4

5

very often happened 
6. Do you have the feeling that you are in an unfamiliar situation and don't know what to do?
1
2
3
4
5
6
7

very often

very

seldom or

never

7. Doing the thing you do every day is:

1

2

3

4

5

6

7

a source of deep

pleasure and

satisfaction

8. Do you have very mixed-up feelings and ideas?

2

3

4

5

6

7

very often

9. Does it happen that you have feelings inside you would rather not feel?
1
2
3
4
5
6
7

very often

very

seldom or

never

10. Many people - even those with a strong character - sometimes feel like sad sacks (losers) in certain situations. How often have you felt this way in the past?
1
2
3
4
5
6
7

never

very often

11. When something happened, have you generally found that:

$\begin{array}{llllllll}1 & 2 & 3 & 4 & 5 & 6 & 7\end{array}$

you overestimated

you saw

or underestimated

things in

its importance

the right

proportion 
12. How often do you have the feeling that there's little meaning in the things you do in your daily life?

$\begin{array}{lllllll}1 & 2 & 3 & 4 & 5 & 6 & 7\end{array}$

very often

very

seldom or

never

13. How often do you have feelings that you're not sure you can keep under control?

1

2

3

very often

seldom
4

5

6

7

very 


\section{Appendix B}

\section{Email Recruitment}

Subject: Are you a thriving nurse?

One of your peers has described you as a thriving nurse. Is that how you think of yourself?

If you:

- $\quad$ Self-describe as thriving

- Experienced (10+ years working as a nurse)

- Or recently retired nurse (within 1 year)

Please consider being a participant in a research study on thriving nurses. This study will involve approximately 20 minutes of your time to complete a survey.

Note: Study participation is confidential. No identifying information will be collected other than age, gender, ethnicity, education level and years of RN experience. No data will be reported in such a way that any participant could be identified.

Interested in participating? Please email me at: elstock@ hawaii.edu

Do you know a thriving nurse? If so, please forward this e-mail to them!

Eleanor Stock, SONDH Honors Program

Estelle Codier, Honors Advisor 


\section{Appendix C}

\section{Sigma Theta Tau Newsletter Recruitment}

Are you a thriving nurse?

Nursing is a career in which both mind and body are constantly challenged. The combination of physical, mental, and emotional strain can leave nurses feeling drained and depleted. However, some nurses are able to thrive in an environment that is extremely demanding. How are these nurses different? I think the answer is important. I wonder what makes certain nurses thrive, even when they are constantly faced by stressors and strains. If you are a thriving nurse who meets the following criteria, this is an invitation to participate in a nursing research study, whose goal is to find out what makes you, the thriving nurse, different!

If you:

- Self-describe as thriving

- Experienced (10+ years working as a nurse)

- Or recently retired nurse (within 1 year)

Please consider being a participant in a research study on thriving nurses. This study will involve approximately 20 minutes of your time to complete a survey.

Note: Study participation is confidential. No identifying information will be collected other than age, gender, ethnicity, education level and years of RN experience. No data will be reported in such a way that any participant could be identified.

Interested in participating? Please email me at: elstock@ hawaii.edu

Eleanor Stock, SONDH Honors Program

Estelle Codier, Honors Advisor 


\section{Appendix D}

\section{Email Response to Interest in Participation}

Thank you for your interest in the research study, "Exploring salutogenesis as a concept of health and wellbeing in nurses who thrive professionally"

The study participation involves a two-part online questionnaire. The first questionnaire consists of five open ended questions that explore the concept, "thriving nurses." The second part of the questionnaire consists of 13 multiple choice questions that are used to determine a person's sense of coherence. This scale was developed by Antonovsky, who posited that thriving was related to a personal sense of coherence.

The study was awarded exempt status by the University of Hawaii Human Subjects Committee. Study participation is confidential. No identifying information will be collected other than age, gender, ethnicity, education level and years of $\mathrm{RN}$ experience. No data will be reported in such a way that any participant could be identified.

The link to the questionnaire is below:

https://www.surveymonkey.com/r/nurse-thrive

Eleanor Stock, SONDH Honors Program.

Dr. Estelle Codier, Honors Advisor. 


\section{Appendix E}

\section{University of Hawai'i: Consent to Participate in Research}

Exploring salutogenesis as a concept of health and wellbeing in nurses who thrive professionally

My name is Eleanor Stock. I am an undergraduate student at the University of Hawaii (UH) Nursing program. As part of the requirements for the University of Hawaii's Honors program, I am doing a research project. The purpose of this project is to explore whether properties of salutogenesis can be seen in nurses who self-describe themselves as "thriving" professionally. You are being invited to participate as someone has described you as "thriving."

Project Description - Activities and Time Commitment: If you decide to take part in this project, you will be asked to fill out an online survey. The questionnaire consists of two parts. The first section involves answering five open ended questions, and the second part involves answering thirteen multiple choice questions. The survey is accessed on a website which I will provide you with a link to. The questionnaire will take approximately twenty minutes of your time. I expect approximately ten people will take part in this project.

Benefits and Risks: There will be no direct benefit to you for taking part in this project. The findings from this project may help create a better understanding of whether salutogenic properties can be seen in nurses who self-describe themselves as "thriving" professionally. There is little risk to you in participating in this project.

Confidentiality and Privacy: All data collected via Survey Monkey is anonymous. I will not ask you for any personal information, such as your name or address. Only my University of Hawaii advisor and I will have access to the research data for analysis. When results of the research project are reported, no data will be reported in such a way that any participant could be identified. Please do not include any personal information, such as names in your survey responses.

Voluntary Participation: Your participation in this project is completely voluntary. You may stop participating at any time. If you stop participation in the study, there will be no penalty or loss to you.

Questions: If you have any questions about this study, please email me at [elstock@ hawaii.edu]. You may also contact my adviser, Dr. Estelle Codier, at [codier@ hawaii.edu]. If you have questions about your rights as a research participant, you may contact the UH Human Studies Program at808.956.5007 or uhirb@ hawaii.edu.

To Access the Survey: Please go to the following web page:

(https://www.surveymonkey.com/r/nurse-thrive). You should find a link to the survey and instructions for completing it are attached in the email. Completing the survey will be considered as your consent to participate in this study.

Please print a copy of this page for your reference. 


\section{References}

Antonovsky, A. (1996). The salutogenic model as a theory to guide health promotion. Health Promotion International, 11(1), 11-18.

Dudovskiy, J. (2016). Snowball Sampling. Retrieved from http://researchmethodology.net/sampling/snowball-sampling

Eriksson, M., \& Lindström, B. (2005). Validity of Antonovsky's Sense of Coherence Scale: a systematic review. Journal Of Epidemiology \& Community Health, 59(6), 460-466 7p.

Grove, S., Gray, J., \& Burns, N. (2015). Understanding nursing research. St. Louis, MO: Elsevier Saunders

Haoka, T., Sasahara, S., Tomotsune, Y., Yoshino, S., Maeno, T., \& Matsuzaki, I. (2010). The effect of stress-related factors on mental health status among resident doctors in Japan. Medical Education, 44(8), 826-834 9p. doi:10.1111/j.1365-2923.2010.03725.x

Institute of Medicine. (2010). The future of nursing: Focus on education. Retrieved from, http://www.nationalacademies.org/hmd/ /media/Files/Report\%20Files/2010/The-Futureof-Nursing/Nursing\%20Education\%202010\%20Brief.pdf

Rushton, C., Batcheller, J., Schroeder, K., \& Donohue, P. (2015). Burnout and resilience among nurses practicing in high-intensity settings. American Journal Of Critical Care, 24(5), 412-421 10p. doi:10.4037/ajcc2015291

Lindström, B., \& Eriksson, M. (2006). Contextualizing salutogenesis and Antonovsky in public health development. Health Promotion International, 21(3), 238-244 7p. doi:heapro/daI016 
Mahammadzadeh, A., Poursharifi, H., \& Alipour, A. (2010). Validation of sense of coherence (SOC) 13-item scale in an Iranian sample. Procedia Social and Behavioral Sciences, 5, $1451-14555 \mathrm{p}$.

Merriam-Webster. (2016). Burnout. Retrieved from http://www.merriamwebster.com/dictionary/burnout

Rabin, S., Matalon, A., Maoz, B., \& Shiber, A. (2005). Keeping doctors healthy: a salutogenic perspective. Families, Systems \& Health: The Journal Of Collaborative Family Healthcare, 23(1), 94-102 9p.

Sigma Theta Tau International. (2016). STTI Organizational Fact Sheet. Retrieved from http://www.nursingsociety.org/connect-engage/about-stti/sigma-theta-tau-internationalorganizational-fact-sheet

Sullivan, G. (1989). Evaluating Antonovsky's Salutogenic Model for its adaptability to nursing. Journal Of Advanced Nursing, 14(4), 336-342 7p. doi:10.1111/j.13652648.1989.tb03421.x

University of Hawaii at Manoa. (2015). Protecting Research Participants. Retrieved from, https://www.hawaii.edu/researchcompliance/information-research-participants 